\title{
NECESIDAD, LO QUE DEPENDE DE NOSOTROS Y POSIBILIDADES ALTERNATIVAS EN LOS ESTOICOS. RÉPLICA A RICARDO SALLES
}

\author{
MARcelo D. Boeri \\ Instituto de Filosofía \\ Universidad de los Andes (Chile) \\ mboeri@uandes.cl
}

RESUMEN: Ésta es la respuesta a la crítica hecha por Ricardo Salles a mi interpretación del compatibilismo estoico. Aunque en parte admito sus objeciones, intento mostrar que algunos textos nos permiten pensar que, aunque lo que depende de nosotros no implique necesariamente acciones alternativas, eso no significa que no pueda implicarlas. También trato de mostrar que un reexamen de la noción crisipea de posibilidad que tenga en cuenta el deseo y la creencia permite explicar por qué no es posible (en el sentido de "posibilidad específica") llevar a cabo las acciones $X$ e $Y$ (o $Y$ en vez de $X$ ) en un tiempo dado, lo cual indicaría que la posibilidad específica también excluye acciones alternativas.

PALABRAS CLAVE: fatalismo, responsabilidad, posibilidad, acciones alternativas, estoicismo

SUMMARY: This is the reply to Ricardo Salles' criticism of my interpretation of the Stoic compatibilism. Although I partially admit his objections, I intend to show that some texts allow us to think that, even though what depends on us does not necessarily imply alternative actions, this does not mean that it can not imply them. I also endeavour to show that a re-examination of the Chrysippean notion of possibility taking into account desire and belief permits to explain why it is not possible (in the sense of "specific possibility") to perform the actions $X$ and $Y$ (or $Y$ instead of $X$ ) in a given time, which would indicate that the specific possibility rules out alternative actions as well.

KEY WORDS: fatalism, responsibility, possibility, alternative actions, Stoicism

Los estoicos antiguos son los primeros filósofos de los que tenemos noticia que hicieron un esfuerzo por mostrar la razonabilidad de la tesis según la cual todo sucede por "destino". En la medida en que sostuvieron que todo estado y acontecimiento son necesitados por una causa antecedente, los estoicos fueron deterministas, pero, al mismo tiempo, fueron compatibilistas, pues creyeron que, aun admitiendo que todo tiene una causa antecedente, puede atribuirse responsabilidad a las acciones humanas. Desdichadamente, el estado lamentable en el que han llegado hasta nosotros las obras de los filósofos estoicos antiguos y medios muchas veces condiciona la manera en que interpretemos sus tesis y argumentos, pues lo que se requiere es una verdadera tarea de reconstrucción de su pensamiento. 
Eso es lo que, al menos en parte, intenté hacer hace unos años cuando me propuse examinar el problema del determinismo estoico en una serie de estudios que, ahora, gracias a la nota crítica del profesor Ricardo Salles, han salido del olvido. En primer lugar, debo destacar la cuidadosa lectura que Salles ha hecho de mis trabajos, un hecho que en sí mismo merece ya mi sincero reconocimiento. En segundo lugar, quisiera destacar el cuidado y el rigor con que ha expuesto mis ideas: efectivamente, el núcleo de mi interpretación en esos trabajos es que, aun manteniendo su determinismo, los estoicos abrieron un margen de indeterminación para hacer lugar a la atribución justificada de responsabilidad. Es cierto también que, en mi opinión, los estoicos habrían concedido al incompatibilista que hay una cierta tensión entre determinismo y responsabilidad y que, en ese sentido, al menos Crisipo parece haber evitado caer en una posición que podría rotularse como "determinista dura", la cual excluiría el merecimiento de elogio o censura a nuestras acciones. Es por eso que en el momento de redactar esos artículos pensé — probablemente influido por el modo aristotélico de ver las cosas- que los estoicos se vieron obligados a dejar abierto un margen de indeterminación, de modo de desactivar la objeción de la que serían pasibles como "deterministas duros". Mi posición, por lo tanto, debería incluirse entre la de los que creen que somos responsables de una acción que hemos llevado a cabo sólo si tenemos la libertad de actuar de otro modo.

El enfoque de Salles es, dicho de un modo muy general, opuesto al mío en lo fundamental, pues lo que él quiere mostrar es que, en realidad, los estoicos no dejaron abierto ningún margen de indeterminación para nuestras acciones y su psicología, no obstante lo cual siguieron creyendo que era posible la atribución justificada de responsabilidad en el contexto de una teoría determinista estricta. Salles cree, además, que si los estoicos hubiesen estado dispuestos a aceptar lo que llama "tesis incompatibilista fuerte" (cfr. p. 95), habrían tenido que abrir un margen de indeterminación dentro de su teoría de la acción y de su sistema causal, como sugiero yo, para dar cabida a la responsabilidad. En su opinión, sin embargo, no hay pruebas textuales decisivas que demuestren que los estoicos estuvieron dispuestos a hacer esta concesión. Dado que los argumentos de Salles son muy medulosos y, en algunos casos, complejos, me permito detallar algunos de los puntos principales de su crítica. En primer lugar, me atribuye dos tipos de argumentos para defender mi posición: (i) los textuales (AT) y (ii) los conceptuales (AC), aunque dice que únicamente se concentrará en los de tipo conceptual y, en particular, en las nociones de "lo que depende de nosotros" y de 
"posibilidad de acciones alternativas". La relación que yo establezco entre estas dos nociones será el blanco principal de su ataque. En la parte central de su crítica Salles reformula mi interpretación resumiéndola convenientemente en dos argumentos; en su opinión, ambos argumentos son válidos, aunque alberga serias dudas respecto de la verdad de sus premisas y, en especial, sobre si los estoicos aceptaron tales premisas; quisiera detenerme en las premisas y la conclusión del primer argumento, pues la primera objeción de Salles se concentra en la segunda premisa de ese argumento:

1. sólo somos responsables de lo que depende de nosotros;

2. sólo dependen de nosotros aquellas acciones que podemos o bien realizar o bien no realizar, esto es, la noción de algo que "depende de nosotros" presupone la noción de acciones alternativas ("premisa 2a"; cfr. Salles p. 87);

3. el determinismo excluye que haya acciones alternativas (si mis acciones tienen una causa antecedente, no es posible que yo pueda o bien llevar a cabo o bien no llevar a cabo mis acciones).

4. Por consiguiente, la responsabilidad es incompatible con el determinismo aplicado a sus acciones y psicología.

Para someter a prueba la verdad de la premisa 2, Salles propone revisar la expresión griega que habitualmente se traduce por "lo que

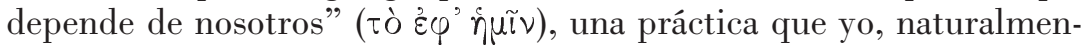
te, también he seguido, pues la dificultad que se plantea en torno de esta premisa es la de si la noción de algo que depende de nosotros en realidad implica la de acciones alternativas, como yo supongo. Todas las razones que ofrece Salles sobre el significado de la expresión en cuestión son sin duda ciertas y, por lo demás, bastante evidentes: દ̇đí con dativo tiene sentido locativo (con lo cual deberíamos decir "lo que está en nosotros") o causal, lo cual significa que cuando se dice $\tau \grave{\varepsilon} \hat{\varepsilon} \varphi$ ' $\tilde{\eta} \mu \tilde{\imath} \nu$ lo que se quiere sugerir es que la causa de algo que "depende de nosotros" somos nosotros mismos. Obviamente, estoy completamente de acuerdo con eso. Hay sobrados ejemplos en los

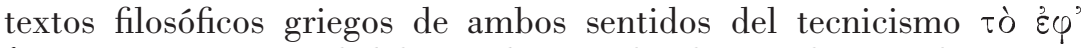
i்ĩ , pero en especial del sentido causal. El ejemplo más ilustrativo del uso filosófico de la expresión es Aristóteles, quien en sus investigaciones morales la introduce para referirse a lo que es objeto de

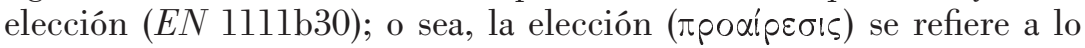
que depende de nosotros en el sentido causal de que elegimos aquello 
de lo que podemos ser causas nosotros mismos. Así, aunque podemos tener el deseo (racional) de ser felices, no podemos elegir ser felices. Ser felices no depende de nosotros pues, aun cuando uno haga todo lo que tiene que hacer para ser feliz — como formar adecuadamente sus estados de carácter, entrenar apropiadamente sus facultades cognoscitivas, etc. - hay imponderables que no dependen del agente. Por ejemplo, todos estamos expuestos a sufrir un accidente del que no seamos responsables, una enfermedad o ciertos hechos azarosos, cuya causa es indefinida. El siguiente ejemplo del uso de la expresión tò

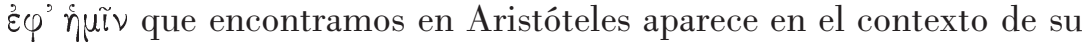
discusión de la deliberación (EN 1112a30-31) y, una vez más, enfatiza el sentido causal. No deliberamos sobre lo necesario ni tampoco sobre lo azaroso, ya que no tenemos ningún poder causal sobre los sucesos necesarios ni sobre los azarosos. Sobre lo primero porque no podemos modificarlo (por ejemplo, el pasado es necesario porque, no importa lo que hagamos, no puede ser de otro modo. De la misma manera la suma de los ángulos interiores de un triángulo es necesariamente 180 grados y no podemos hacer nada para modificar ese hecho). Que los sucesos azarosos no dependen de nosotros es también obvio para Aristóteles, pues no podemos hacer nada para intervenir causalmente en un suceso azaroso que, en su opinión, es de tal índole, precisamente, porque su causa es indefinida. ${ }^{\circledR}$ El objeto de la deliberación son las acciones humanas que pueden ser de otro modo, porque no toda acción humana puede ser de otro modo. Las acciones pasadas son necesarias y no pueden ser de otro modo que como ya son, de manera que no se delibera tampoco sobre el pasado. Pero incluso sobre otro tipo de acciones que todavía no han sucedido: ningún espartano delibera sobre el modo en que los escitas estarían mejor gobernados pues nada de esto, argumenta Aristóteles, podría ocurrir a través de nosotros ( $\delta \iota^{`} \dot{\eta} \mu \widetilde{\omega} \nu ; E N$ 1112a30).

Me interesa señalar esta expresión — que en el lenguaje aristotélico

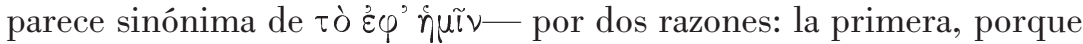
reaparece en algunos textos atribuidos a los estoicos; la segunda porque, como es evidente en el pasaje de $E N$ recién citado, si tò $\varepsilon \varphi^{\prime} \dot{\eta} \mu \tilde{\imath} \nu$ y $\delta \iota^{\prime} \dot{\eta} \mu \widetilde{\omega} \nu$ son sinónimos, Aristóteles está interesado en subrayar el valor causal de "lo que depende de nosotros". ${ }^{2}$ No hace falta, por lo tanto, recurrir a la traducción de Cicerón del griego

1 Cfr. Boeri 1995.

${ }^{2}$ Véase también Ética Eudemia 1223a7-9, donde queda claro, una vez más, que lo que depende del agente es aquello de lo que él mismo es causa. 


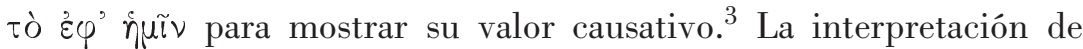
Cicerón de la expresión griega sería, en todo caso, un aspecto menor del asunto, pues yo estaría dispuesto a traducir $\tau$ ò $\varepsilon \varphi^{\prime} \dot{\eta} \tilde{\mu} \nu$ por "lo que está en nuestro poder", con lo cual no veo ningún cambio de fondo: lo que está en nuestro poder (o depende de nosotros) se refiere a acciones que podemos o bien llevar a cabo o bien no llevar a cabo, acciones de las que nosotros mismos como agentes somos "causa". La objeción de fondo que Salles hace en este punto es examinar las razones que tenemos (o que yo tengo) para pensar que los estoicos usaron el concepto de $\tau$ ò $\hat{\varepsilon} \varphi^{\circ} \dot{\eta} \mu \tilde{\imath} \nu$ como si implicara acciones alternativas, por lo cual señala que un examen léxico de la expresión no basta para decidir el asunto. Salles sostiene que no hay pruebas textuales de que algún estoico temprano haya usado el concepto de "lo que depende de nosotros" en un sentido que,

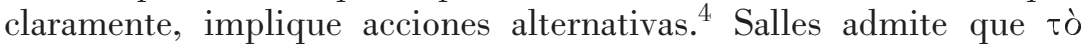

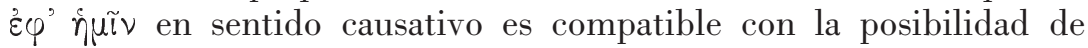
acciones alternativas, pero el que sean compatibles no significa que una cosa implique la otra. En este importante detalle reside, en mi opinión, el núcleo de la objeción de Salles a una parte sustancial de mi interpretación. En efecto, en mi argumento entendí que la noción de lo que depende de nosotros implica acciones alternativas; lo que Salles me está objetando con razón es que debí haber demostrado que los estoicos usaron estas nociones en este sentido (algo que no he hecho), no que nunca y en ningún caso es posible que lo uno implique lo otro. Como el mismo Salles lo admite, fue nada menos que Aristóteles quien usó las nociones de lo que depende de nosotros y de acciones alternativas en el sentido de que lo primero implica (o "conlleva", como matiza Salles la relación entre lo uno

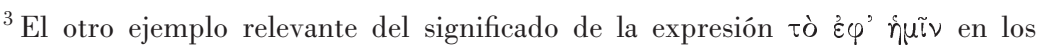
textos filosóficos es, claro está, Alejandro de Afrodisia; una preocupación especial de Alejandro en contra de los que dicen que "todo sucede según el destino" (probablemente los estoicos) consiste en mostrar que esta posición no sería capaz de "salvar" ( $\sigma \omega \zeta \zeta \varepsilon \sigma \vartheta \alpha)$ lo que depende de nosotros, que él entiende como "la autodetermi-

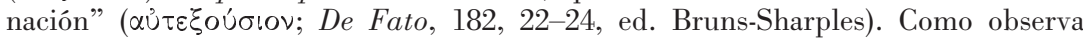
Bobzien (1998, p. 408, n. 111), Alejandro parece enfatizar el hecho de que sus oponentes (¿los estoicos?) no advirtieron el significado de este término para implicar la libertad indeterminista del agente, lo cual presupondría que tenga el poder de hacer/elegir un curso de acción o su opuesto. Esto, naturalmente, no significa que

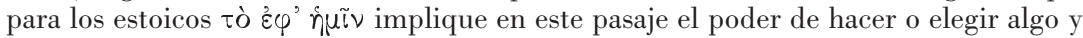
su opuesto. Véase, sin embargo, Alejandro, De Fato 176, 14-25 (ed. Bruns-Sharples), citado y comentado al final de este trabajo.

${ }^{4}$ Aunque admite que en el estoico tardío Epicteto parece darse; cfr. Salles 2005, p. 110 (citado por Salles en su nota 12, p. 89). Véase, de nuevo, Alejandro, De Fato $176,14-25$. 
y lo otro) lo segundo. Yo estoy dispuesto a aceptar que lo primero no implica necesariamente lo segundo, pero eso no significa que no pueda implicarlo. En este punto se me puede acusar de "aristotelizar" a los estoicos, pero no creo que su argumento en este punto sea conclusivo para mostrar que no es posible que lo que depende de nosotros pueda implicar acciones alternativas. ${ }^{5}$

Aunque Salles advierte al comienzo de su nota que no se ocupará de lo que llama AT, concluye su primer grupo de objeciones a la premisa 2a del Argumento 1 usando un AT y señalando que no cree que se puedan hallar pruebas de que algún estoico temprano haya usado el concepto de "lo que depende de nosotros" en un sentido que implique acciones alternativas en el pasaje de Cicerón, De Fato 39-44, aunque, al mismo tiempo admite que este discutido pasaje puede tener una lectura indeterminista como la que yo defiendo. ${ }^{6}$ Este texto es, como se sabe, clave para reconstruir algunas teorías del estoico Crisipo sobre la causalidad, y en él, además de una distinción detallada de diferentes formas de causalidad, uno se encuentra con la noción de "lo que depende de nosotros" — o, si se quiere ponerlo en la traducción ciceroniana de la expresión griega, "lo que está en nuestro poder" (in nostra potestate; Cicerón, De Fato, 41) - desempeñando un papel fundamental. Aunque Salles no se propone tratar los AT, sino sólo los AC, creo que hay que hacer una referencia, al menos breve, de ese texto ya que él lo menciona en el contexto de su discusión de los AC (lo cual parecería mostrar que no pueden tratarse los AC independientemente de los AT, pues, en buena medida, lo que estamos tratando de establecer es qué dijeron los estoicos sobre la necesidad, lo que depende de nosotros y la atribución justificada de responsabilidad). El argumento que Cicerón atribuye a Crisipo en De Fato 41-43 puede esquematizarse en los siguientes pasos:

(i) Crisipo desaprueba la necesidad pero al mismo tiempo pretende que todo sucede por causas antecedentes.

5 Por lo demás, tengo la impresión de que respecto de la posible "aristotelización" de los estoicos se produce una especie de "círculo hermenéutico", pues con frecuencia utilizamos textos de autores peripatéticos (como Alejandro de Afrodisia) para reconstruir algunas teorías estoicas y, con la misma frecuencia, descalificamos la interpretación de algunos de esos autores argumentando que se trata de un enfoque aristotélico que los estoicos no pueden haber avalado. No estoy sugiriendo ni implicando que Salles haga esto en su argumento.

${ }^{6}$ Cfr. Salles, p. 96, nota 18, aunque en el modo en el que reconstruyo abajo el argumento de Crisipo en el De Fato de Cicerón tiendo a admitir una lectura más determinista que la que hice en los trabajos a los que se refiere ahora Salles. 
(ii) Ambas posiciones parecen incompatibles, i.e. escapar a la necesidad (necessitas) y mantener el destino (fatum).

(iii) Para escapar a la posible incompatibilidad descrita en (ii), Crisipo distingue dos tipos de causa: (a) las perfectas y principales y (b) las auxiliares y próximas. Esto, según Cicerón, le permite a Crisipo reformular su tesis de que todo sucede por destino (omnia fato fieri) de la siguiente manera: todo sucede según destino por causas antecedentes, no por causas principales.

(iv) Ahora bien, hay cosas que están en nuestro poder y cosas que no; las causas antecedentes no están en nuestro poder, las perfectas y principales sí. Esta nueva distinción le permite a Crisipo argumentar en contra de los que sostienen que, si se introduce el destino, todo sucede por destino únicamente (una causa antecedente, según Crisipo), lo cual significa que también sucede por destino el impulso (adpetitus; De Fato 40), ${ }^{7}$ lo que se sigue de él, y los actos de asentimiento (adsensiones), que es lo mismo que decir que ninguno de ellos depende de nosotros (ne... in nostra potesta). Dicho de otro modo, si ni el impulso ni el asentimiento están en nuestro poder, tampoco lo estará la acción. $^{8}$

(v) Pero con la distinción de tipos de causa, Crisipo puede hacer frente a esa objeción pues los asentimientos e impulsos no se hacen por causas antecedentes, sino por perfectas y principales (De Fato 41).

(vi) Ahora bien, si las causas auxiliares y próximas (i.e., antecedentes) no dependen de nosotros, no se sigue que tampoco el impulso (adpetitus; De Fato 41) dependa de nosotros (sit in nostra potestate). Eso ocurriría únicamente en el que caso de que se admitiera que todo sucede por causas perfectas y principales y que tales causas no dependen de nosotros (quod non).

(vii) Pero como el impulso y el asentimiento son causas principales y las causas principales dependen de nosotros, puede concluirse que el impulso y el asentimiento no están determinados solamente por el destino, sino también por nosotros (De Fato 43).

${ }^{7}$ Ésta es la traducción de Cicerón del griego ópuŕ.

8 Salles reconstruye esta parte del argumento de un modo mucho más detallado y preciso en Salles 2005, pp. 40-41. 
Ahora bien, Salles argumenta que, aunque se acepte que lo que depende de nosotros es compatible con la posibilidad de acciones alternativas, eso no significa que lo primero necesariamente implique lo segundo; he sugerido que, aunque se acepte esta objeción, eso no significa que lo primero no pueda implicar lo segundo. En la explicación de la psicología de la acción que Cicerón atribuye a Crisipo la representación (visum) —que no está en nuestro poder o no "depende de nosotros" - es la causa antecedente del asentimiento y del impulso (y, en ese sentido, los determina), los cuales están en nuestro poder. Por otras fuentes, ${ }^{9}$ sabemos que los estoicos pensaron que el agente puede dar o rehusarse a dar su asentimiento a la representación o, más precisamente, a la proposición que es dicha representación. Por eso me parece al menos razonable suponer que en el De Fato de Cicerón el asentimiento depende del agente racional y que éste puede asentir o no asentir a la representación. En este sentido, creo que es apropiado entender que, al menos para Crisipo, lo que depende de nosotros puede implicar posibilidades alternativas: los actos de asentimiento dependen de nosotros en el sentido de que la causa del asentimiento somos nosotros mismos. Pero además podemos asentir a una proposición o rehusarnos a asentir a ella, y ésas son posibilidades alternativas.

El segundo grupo de objeciones se centra ahora en la segunda premisa del segundo argumento (para el cual, en vista de la brevedad, remito al lector a la nota de Salles (p. 87)):

(2b): el determinismo excluye que se dé la posibilidad de acciones alternativas $[\ldots]$.

Para reforzar su crítica, Salles propone distinguir entre "posibilidad general" y "posibilidad específica", de modo de mostrar que, en contra de mi posición, sí hay un sentido en el que la posibilidad de acciones alternativas es compatible con el determinismo, a saber, si se trata de la "posibilidad general". Según la posibilidad específica, el agente en un momento $t$ tiene dicha posibilidad específica de llevar a cabo las acciones alternativas $X$ e $Y$, si y sólo si en $t$ puede llevar a cabo $X$, y, más importante aún para mi argumento, si en $t$ puede llevar a cabo $Y$ en vez de $X$. En este sentido de posibilidad parece que el determinismo excluye la posibilidad de acciones alternativas,

9 Orígenes, De principiis 3.1, 2-3; Plutarco, De stoicorum repugnantiis $1065 \mathrm{~F}$. Para una traducción española de estos pasajes me permito remitir a Boeri 2004, pp. 191-194. 
pues si todo está absolutamente determinado, ${ }^{10}$ el agente no puede llevar a cabo una acción (digamos $Y$ ) en lugar de la otra $(X)$, sino que lleva a cabo la acción que estaba determinado a llevar a cabo (como veremos enseguida, Salles también argumenta en contra de esta inferencia que, en su opinión, no es más que una "apariencia engañosa"). Pero, como agudamente lo muestra Salles, hay otro sentido de posibilidad que debe ser distinguido: un agente puede tener una posibilidad meramente general de llevar a cabo las acciones alternativas $X$ e $Y$ si en $t X$ e $Y$ constituyen acciones que el agente puede llevar a cabo en general, sin importar que el agente no pueda llevar a cabo en $t$ alguna de las dos o incluso ninguna de ellas. En este punto es claro, en mi opinión, que lo que el argumento de Salles muestra es no que no es cierto sin más que el determinismo excluye la posibilidad de acciones alternativas, sino que excluye la posibilidad específica de acciones alternativas. La precisión es importante y, de ser cierta, no parece que pueda concluirse de modo categórico que es falso sin más que el determinismo excluye la posibilidad de acciones alternativas. Uno podría esperar que Salles le diera énfasis a la relevancia de la posibilidad general (algo que, finalmente, no hace), de modo que se desactivara la fuerza de la posibilidad específica que daría cierta razonabilidad a la tesis de que el determinismo excluye la posibilidad de acciones alternativas. Sobre la base del argumento mismo de Salles, entonces, se podría redefinir y precisar mi posición diciendo no que el determinismo excluye la posibilidad de acciones alternativas, sino que excluye la posibilidad específica de acciones alternativas.

Para mostrar que, en efecto, puede hacerse esta importante distinción entre posibilidad específica y general, Salles señala con razón que casi nunca es claro, en un autor antiguo que habla de la posibilidad de acciones alternativas o la implica, si se refiere a la posibilidad general o específica, y a continuación cita el conocido pasaje de Aristóteles de Ética Eudemia, 2.10, 1226a20-28, y agrega que "Aristóteles no indica en este pasaje si se está refiriendo a la posibilidad de que algo "sea y no sea' en un momento específico [...] o a la posibilidad de que algo "sea y no sea' en general" (p. 90). Pero si Aristóteles deja abierta la cuestión de a qué tipo de posibilidad se refiere, nada impide que la interpretemos en uno u otro sentido. Además, los ejemplos que da Aristóteles para mostrar algo que no depende de nosotros y que, por

${ }^{10}$ Este modo de expresar el asunto daría lugar a pensar que los estoicos avalaron un fatalismo burdo, una posición que Salles no suscribe ( $c f r$. Salles 2005, pp. 9-12) y sobre la cual yo tengo algunas dudas ( $c f r$. Boeri 2007). 
lo tanto, no se trata de algo sobre lo que debamos deliberar indican, claramente en mi opinión, que está pensando que entiende "lo que depende de nosotros" en el sentido causal de que no es posible que nosotros seamos la causa ahora (posibilidad específica) ni que podamos serlo en el futuro (posibilidad general) de los sucesos descritos. Por lo menos el ejemplo de la posibilidad de cuadrar el círculo no depende de nosotros, ni en el sentido de posibilidad específica ni en el de posibilidad general.

Pero Salles, probablemente previendo que subrayar la "posibilidad general" ofrece un flanco débil a su posición en la medida en que yo podría reformular mi interpretación argumentando que el determinismo excluye la posibilidad específica de acciones alternativas, afirma ahora que responder de manera negativa a la pregunta de si la posibilidad específica de acciones alternativas es compatible con el determinismo causal es solamente una "apariencia engañosa" (cfr. Salles, sección 4), ya que hay al menos un sentido en el que la posibilidad específica de acciones alternativas es compatible con la necesidad causal. Para mostrar su última objeción y terminar de demoler mi interpretación Salles recurre a la definición - probablemente

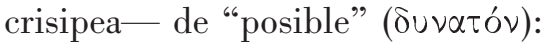

posible es lo que admite ser verdadero y a lo que no se le opone nada

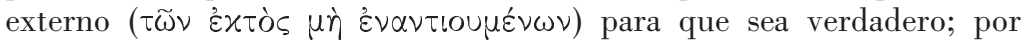
ejemplo, Dión vive (Diógenes Laercio 7.75)

que Salles interpreta de la siguiente manera: un agente $A$ tiene en $t$ la posibilidad específica tanto de llevar a cabo $X$ como $Y$ (o $Y$ en vez de $X)$ si $A$ tiene en $t$ la fuerza física necesaria tanto para llevar a cabo $X$ como $Y$, y si no hay ninguna circunstancia externa que le impida a $A$ ejercer esa fuerza. Destaco "fuerza física" y "ejercer esa fuerza" porque en la definición de posible no aparece nunca esa prescripción, sino que se trata de un agregado de Salles que resulta importante en su argumento. Como él lo reconoce, no tenemos precisión con respecto a qué tipo de capacidad es la que imagina aquí Crisipo, aunque, como se ha sugerido, puede haber pensado en una capacidad física. Según la definición crisipea, es posible que la proposición "Dión vive" sea verdadera si en el momento en que se la enuncia Dión no recibe una descarga eléctrica de 3.500 voltios de electricidad (éste es un ejemplo de "lo externo" o "las circunstancias externas" que impedirían que la proposición sea verdadera). La definición re-

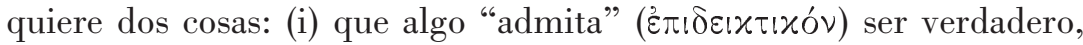


y (ii) que nada externo lo impida. El ejemplo al que recurre Salles se basa en el hecho de que (i) se refiere a ciertas condiciones físicas que puede tener un agente ( $c f r$. en la sección 4 , su ejemplo de permanecer inmóvil y la fuerza física que uno debe tener). Según el argumento de Salles, si $A$ tiene sus capacidades físicas en buenas condiciones y si en $t$ nada externo lo impide, entonces, $A$ tiene la posibilidad específica de llevar a cabo su acción (permanecer inmóvil) o de no llevarla a cabo (caminar), lo cual muestra que hay dos acciones alternativas tales que el agente puede llevar o no llevar a cabo y que, por lo tanto, la posibilidad específica de acciones alternativas es compatible con el determinismo causal. Este ingenioso argumento de Salles para negar que lo que depende de nosotros implica acciones alternativas subraya el hecho de que en este tipo de sistema modal la no necesidad de una proposición es compatible con el hecho de que haya causas suficientes de la acción correspondiente. Es una buena objeción que sirve para mostrar que no sólo la posibilidad general es compatible con el determinismo causal, sino también la posibilidad específica.

Podríamos responder a esto diciendo que, aunque también la posibilidad específica de acciones alternativas sea compatible con el determinismo, se trata de un sentido de posibilidad demasiado débil, y que el tipo de posibilidad que se requeriría para la responsabilidad debería ser más fuerte (esta objeción es visualizada por Salles; cfr. la sección 5). Hay una razón para preferir la relevancia de la posibilidad específica y no la general, pues en tanto ésta no se refiere a acciones concretas hic et nunc, sino a acciones que en circunstancias diferentes de las actuales tendré la posibilidad de realizar, la posibilidad específica, en cambio, tiene una especial fuerza explicativa respecto de lo que el agente lleva a cabo de modo efectivo en el momento en que lo lleva a cabo. Salles advierte este hecho y está dispuesto a admitir que, aunque la posibilidad específica de acciones alternativas es compatible con el determinismo, se trata de un sentido demasiado débil de posibilidad. Pero él cree que los estoicos no se sintieron afectados por esta objeción pues si ése hubiese sido el caso, habrían tenido que abrir un margen de indeterminación en su sistema causal y de teoría de la acción, como sugiero yo, un hecho sobre el cual, argumenta Salles, no hay pruebas textuales decisivas (regreso a este punto enseguida en el último párrafo).

Ahora bien, para intentar restarle fuerza al ingenioso argumento de Salles sobre la noción crisipea de "posible" se podría argumentar lo siguiente: no es para nada claro que en el requisito (i) de su definición de posible Crisipo esté pensando en una fuerza o capacidad física; hasta donde puedo ver, eso no explica la lacónica sentencia 


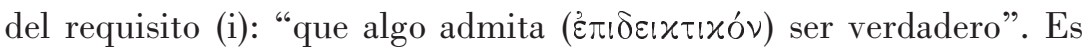
cierto que si la acción es "permanecer inmóvil", es razonable pensar que una condición de esa acción es estar en condiciones físicas apropiadas (si uno tiene Parkinson, no podrá permanecer inmóvil), pero, como argumentaré enseguida, no parece ser ésa la única descripción posible de lo que significa "admitir ser verdadero". Si entiendo bien la definición de "posible" que da Crisipo, los dos requisitos (i) y (ii) deben darse juntos; no basta con que se dé (i) ni tampoco basta con que solamente se dé (ii). Para que la acción sea posible deben darse (i) y (ii) juntos; pero además — sobre todo en el caso de contextos prácticos - también deben darse otras condiciones, como desear llevar a cabo una acción o creer que debo llevar a cabo la acción. ${ }^{11}$ No importa que se den (i) y (ii): si tengo la fuerza física para caminar y no hay ningún obstáculo que me impida hacerlo, de todos modos, no caminaré si no deseo hacerlo o si no creo que sea apropiado hacerlo. Es cierto que eso no significa que no pueda hacerlo en el sentido de la posibilidad general, pero en tanto no desee o no crea apropiado hacerlo, de hecho, no puedo hacerlo en el sentido de la posibilidad específica de llevar a cabo la acción $X$ e $Y$ (o $Y$ en vez de $X$ ) en $t$. Para ponerlo en un ejemplo: supongamos el caso de una persona que está sentada bajo un árbol en un día de calor; a pocos metros de ella puede haber un caballo que también trata de refugiarse del calor, y a pocos metros de ambos puede haber un espejo de agua. Tanto el humano como el caballo tienen apetito, i.e., un tipo de deseo que les dice "hay que beber"; pero si el agente racional tiene al menos una evidencia superficial de que el agua puede estar contaminada — por ejemplo, si el agua presenta un color turbio, emite un olor fétido o si se presenta cualquier otra indicación de esta índole-, probablemente, hará un esfuerzo por contener el apetito o por demorar la satisfacción de su deseo de beber. O sea, aunque en un sentido el agente desea llevar a cabo la acción de beber, en otro sentido no lo desea y es éste segundo sentido de desear el que no hace posible llevar a cabo la acción.

Salles cree además, en contra de mi afirmación de que los estoicos se vieron obligados a abrir un margen de indeterminación, que no hay textos que sin ninguna ambigüedad muestren que para los estoicos algo depende de nosotros sólo si carece de una causa suficiente. Tiendo a pensar ahora que, en este punto en particular, Salles tiene

\footnotetext{
${ }^{11}$ Este modo de enfocar la cuestión en este punto me fue sugerido en parte en un intercambio epistolar con Laura Gómez (Universidad Nacional de Colombia), a quien le estoy agradecido.
} 
toda la razón y no se me ocurre ninguna explicación razonable que oponerle; no obstante, también me atrevería a responder que, naturalmente, no hay ningún texto que pueda mostrar eso sin ninguna ambigüedad, como sucede con muchas otras teorías del estoicismo antiguo. ${ }^{12}$ Creo que Salles también piensa que no hay ningún pasaje estoico en el que pueda verse con claridad que en el uso técnico que probablemente hicieron los estoicos de lo que "depende de nosotros" esta noción implique la de acciones alternativas. Hay, sin embargo, un pasaje en el que los estoicos parecen sugerir la importancia de cursos alternativos de acción en su discusión de lo posible. Se trata de un texto de Alejandro de Afrodisia, que, dada su importancia para mi argumento, me permito citar textualmente:

Argumentar que, $(i)$ si todos los [acontecimientos] suceden según des-

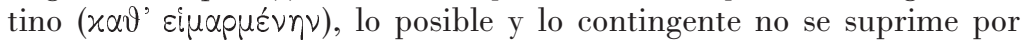
cuanto es posible que suceda $\left(\gamma \varepsilon \nu \varepsilon ́ \sigma \vartheta \alpha_{l}\right)$ aquello que no es impedido de suceder por nada, aun cuando no suceda, y que (ii), entre los [acon-

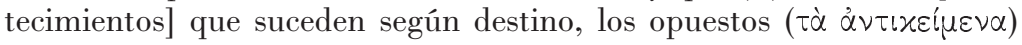
no son impedidos de suceder, por lo cual, sin duda, aunque no sucedan

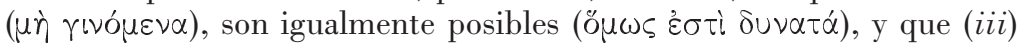
proporciona una prueba de que no se impide que ellos sucedan el hecho de que los impedimentos mismos nos son completamente desconocidos, aun cuando haya algunos — pues las causas de que los opuestos a ellos sucedan por destino son también las causas de que no sucedan, si, como dicen, es imposible que en las mismas circunstancias sucedan hechos opuestos- [...], entonces, argumentar estas cosas, ¿cómo no habrá de ser propio de quienes bromean en argumentos que no requieren broma? En efecto, el hecho de que nosotros ignoremos no significa nada respecto de que los hechos $(\pi p \alpha ́ \gamma \mu \alpha \tau \alpha)$ sean o no sean el caso. (De Fato 176, 14-25; ed. Bruns-Sharples, mi traducción, con elipsis)

Este pasaje se encuentra en uno de los capítulos más oscuros del De Fato de Alejandro; sin embargo, hay cierto consenso en reconocer que lo que está discutiendo es la noción estoica de posible ${ }^{13}$ (que

12 Esa ausencia de ambigüedad en muchos pasajes estoicos hace a veces que uno pueda ofrecer interpretaciones razonables (aunque no necesariamente definitivas) de un mismo texto, pero en direcciones opuestas (como el comentado pasaje de Cicerón, De Fato 41-43, cuya lectura determinista Salles favorece y yo no).

${ }^{13}$ La definición de posible que ofrece en (i) es casi idéntica a la que da Diógenes Laercio 7.75 (citado antes) con la única diferencia de que, en vez de "lo que no es impedido por nada externo", dice "no es impedido de suceder por nada". Como sugiere Natali remitiendo a Cicerón, De Fato 13, y Plutarco, De stoicorum repugnantiis 1055E-F (1996, p. 242), puede tratarse de una "expresión abreviada para decir 


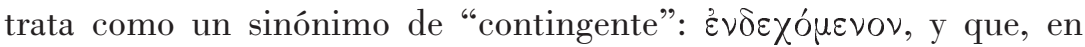
contra de los deterministas (probablemente los estoicos), arguye que las razones que éstos ofrecen para probar que puede mantenerse el destino y lo posible presentan una noción meramente epistemológica de lo posible al argumentar que ignoramos cuáles son los factores que impiden que ocurran las cosas.

Lo que me interesa subrayar de modo especial en el pasaje es el punto (ii): "entre los [acontecimientos] que suceden según destino, los opuestos no son impedidos de suceder, por lo cual, sin duda, aunque no sucedan, son igualmente posibles". Si los estoicos son los deterministas a los que Alejandro está atacando y si este argumento puede razonablemente atribuírseles, entonces, es claro que hay que admitir que los estoicos estaban interesados en mostrar que la tesis de que todo sucede por destino no impide que sucedan "cursos alternativos u opuestos de acción" (en el griego de Alejandro $\tau \grave{\alpha}$ $\dot{\alpha} \nu \tau i x \varepsilon(\mu \varepsilon \nu \alpha)$. Ahora bien, si al mismo tiempo admitieron que hay algo que depende de nosotros, no me parece imposible que lo hayan conectado con "los opuestos"; esto, desde luego, no demuestra que lo que depende de nosotros implica acciones alternativas, pero indica que los estoicos estaban interesados en darle un papel (tal vez importante) a la posibilidad de cursos alternativos en su explicación de la responsabilidad. ${ }^{14}$

\section{BIBLIOGRAFÍA}

Bobzien, S., 1998, Determinism and Freedom in Stoic Philosophy, Oxford University Press, Oxford.

Boeri, M.D., 2007, "[Reseña de] Ricardo Salles, The Stoics on Determinism and Compatibilism" (Ashgate, 2005, Londres, en Bryn Mawr Classical Review, 2007.03 .02 (publicación electrónica: http://ccat.sas.upenn.edu/ bmcr/2007/2007-03-02.html).

—_ 2004, Los estoicos antiguos. Sobre la virtud y la felicidad, Universitaria, Santiago de Chile.

— 1995, "Chance and Teleology in Aristotle's Physics", International Philosophical Quarterly, vol. 35, no. 1, pp. 87-96.

que es posible aquello que ni la propia constitución natural ni las circunstancias externas impiden".

14 Estoy agradecido con Ricardo Salles, quien desde hace más de una década comparte conmigo el entusiasmo por los estoicos, y quien, además, me ha sometido permanentemente a sus inteligentes e implacables críticas y objeciones en un sano espíritu de diálogo. También agradezco a Crítica la posibilidad que me da de responder a la nota crítica de Ricardo. 
Natali, C., 1996, Alessandro di Afrodisia. Il Destino, pref., introd., comentarios, bibliografía e índice de C. Natali, trad. Carlo Natali y Elisa Tetamo, Rusconi, Milán.

Salles, R., 2005, The Stoics on Determinism and Compatibilism, Ashgate, Londres. [Versión en castellano: Los estoicos y el problema de la libertad, Instituto de Investigaciones Filosóficas-UNAM, México, 2006.]

Recibido el 28 de marzo de 2007; aceptado el 25 de abril de 2007. 